\title{
HIV infection and AIDS: the ethics of medical confidentiality
}

\author{
Kenneth M Boyd Secretary, IME working party, on behalf of the working party
}

\begin{abstract}
Author's abstract
An Institute of Medical Ethics working party argues that an ethically desirable relationship of mutual empowerment between patient and clinician is more likely to be achieved if patients understand the ground rules of medical confidentiality. It identifies and illustrates ambiguities in the General Medical Council's guidance on AIDS and confidentiality, and relates this to the practice of different doctors and specialties. Matters might be clarified, it suggests, by identifying moral factors which tend to recur in medical decisions about maintaining or breaching confidentiality. The working party argues that two such factors are particularly important: the patient's need to exercise informed choice and the doctor's primary responsibility to his or her own patients.
\end{abstract}

\section{Medical confidentiality and discretion}

'All that may come to my knowledge in the exercise of my profession or outside of my profession or in daily commerce with men, which ought not to be spread abroad, I will keep secret and will never reveal' (1). The modern Declaration of Geneva reformulates this clause from the Hippocratic Oath as, 'I will respect the secrets which are confided in me, even after the patient has died' (2). These statements show that the medical profession continues to regard confidentiality as a very important moral duty, but does not consider it an absolute one.

The Hippocratic Oath is concerned with discretion as well as with confidentiality, and limits both to what 'ought not to be spread abroad'. The Geneva version, restricted to 'secrets which are confided in me', promises to 'respect' rather than to 'never reveal' them. Both statements, that is, imply that the duty of confidentiality may be qualified by other considerations. Neither version specifies what these considerations might be: but current disciplinary guidelines allow doctors to disclose confidential information in certain exceptional circumstances, when this is judged to be in the interest of the patient

\section{Key words}

AIDS; confidentiality; General Medical Council; mutual empowerment concerned, or (normally when required by law) to be in an overriding public interest (3).

The medical profession's stance on confidentiality and discretion can be morally justified on the understanding that duties originate from relationships, and that medical practice involves relationships of trust both with individual patients and with society. Doctors promise to make 'the health of my patient ... my first consideration', and 'to consecrate my life to the service of humanity' (2). This inevitably calls for trust in the discretion of doctors when the claims of an individual patient conflict with the wider interests of society $\overrightarrow{0}$ generally.

Medical confidentiality serves the patient's health two ways: a free exchange of information in relationship of mutual trust is therapeutically effective, and confidentiality protects the patient's autonomy from being constrained by those outside a trusting relationship gaining access to sensitive personal information. Medical confidentiality also normally serves the common good: most patients either have no secrets which could endanger public health, or, if they do, can be encouraged within a confidential relationship to disclose them voluntarily to whoever has a need to know. It is only in very exceptional cases, when the patient cannot be persuaded to disclose a harmful secret voluntarily, that an exception to the rule may be justifiable. But the doctor's promise to put the patient's health first, means that the onus of proof is on showing that the exception is justified. All of this is only underlined by the fact that in at least one context, $\frac{T}{0}$ sexually transmitted disease (STD) clinics, medical confidentiality is protected by legislation.

\section{HIV Infection and AIDS}

The moral reasons for maintaining or breaching medical confidentiality have not been changed by the advent of AIDS. HIV infection, however, has the potential not only to create a medical pandemic, but $\stackrel{\Phi^{\infty}}{+}$ also to provoke social prejudice. This makes it ${ }^{+}$ especially important to protect patients with HIV ${ }^{-}$ infection or AIDS from casual or unintentional $\vec{\Phi}$ breaches of confidentiality. At the same time, the need $\stackrel{?}{\oplus}$ to control the spread of infection makes it vital that $\varrho$ maintaining confidentiality should serve the common? good as well as that of the individual patient. In some 
cases these goals may be, or may be perceived to be, in conflict.

This paper discusses the ethics of medical confidentiality in such cases. Its approach embodies the view that a relationship of mutual empowerment between clinician and patient serves the ends both of medical beneficence and of patient autonomy. The concept of mutual empowerment is based on the following considerations:

a) The ultimate power of decision-making about their own future normally and properly belongs to patients themselves.

b) Patients, unaided by effective communication, may not possess even the most basic medical information required for choices about their clinical treatment; and they will often be unable to interpret the implications of the state to which their illness has progressed.

c) Clinicians have knowledge and skill which they can not only exercise for the good of patients, but also put at patients' disposal, providing them with the information and practical assistance they require to make and carry out their own responsible decisions.

d) Clinicians cannot do this effectively, unless they in turn are provided by patients with adequate information about their way of life and how they hope to be enabled by their treatment.

A relationship of mutual empowerment, we suggest, is more likely to be realised if patients understand the ground rules of medical confidentiality. With this in mind, we examine the implications of a General Medical Council statement of May 1988 on the subject (see below), with particular reference to different medical contexts and to the patient's informed choice as a significant factor in decisions about medical confidentiality.

We begin with two examples based on simplified scenarios which illustrate the problem under discussion.

\section{John and Jane}

John was in his mid-thirties, married and with two young children, when his company sent him to set up a new branch in Central Africa. He was nine months on his own, and during that time he worked exceptionally hard and successfully, letting himself go only on one regretted occasion when, after a convivial evening with some clients, he visited a local brothel.

By the time John returned home, Jane had found a cottage in her parents' village where their belongings could be stored when they returned to Africa together. To buy the cottage, John needed a small mortgage, and two questions on the form led him from Dr Browne, their family doctor, to a London consultant and back again. It was just good luck, Dr Browne told him, that Jane's gynaecological condition had temporarily prevented them from having intercourse since his return. But John now clearly had no alternative but to tell her that he was HIV-positive.

John loved Jane, but knew her nature, part-Puritan, part-hypochondriac. When he came back to see $\mathrm{Dr}$ Browne after thinking things over, he tried to explain his misgivings about telling her. Dr Browne was unimpressed: John was like a man with a loaded revolver as far as his wife was concerned, he told him. He was also more explicit about his own potential role. His duty of confidentiality towards John was not absolute. Jane also was his patient; and both the General Medical Council and the British Medical Association made it clear that in these circumstances he could breach confidence.

Reluctantly, John told Jane. As he feared, she took his confession extremely badly, becoming quite hysterical and refusing to listen further. She took the children home to her parents, saying that it was not safe for them to be in the same house as him, and shortly after she began divorce proceedings. Before he went back to Africa, John revisited the consultant in London, who discussed his options, gave him some good practical advice, and told him how he might know when it was time to come back. When the time came however, unable to face his situation and the prospect of dying of AIDS, John killed himself.

\section{Tracy and Kevin}

Tracy had always wanted to go on the stage, and after completing her nursing degree had tried it for a time but without much luck. She drifted back into nursing, found she both enjoyed and was good at it, and eventually became a tutor. Her hospital was in a Northern town, in whose amateur dramatic society she soon became very involved. As usual, there was a shortage of men, but for Tracy, Kevin's arrival put that out of her mind. Her only difficulty was to understand why he had given up professional acting.

Dr Macphee also met Kevin, in his walk-in clinic at Tracy's hospital. It was not easy to tell him that he was HIV-positive, even when Kevin replied that he had been half-expecting it, ever since the disastrous season when his professional career and his marriage had both ended in a haze of heroin. He agreed too that Tracy should be told, but when she in turn sat in $\mathrm{Dr}$ Macphee's office, she was in no doubt that her relationship with Kevin should continue. Death was a risk love had to take, she said, but she had not been infected and they were using condoms.

Tracy's confidence was misplaced. Some time later she had a sero-conversion illness and was found to be infected. Shortly before this, their relationship had broken down and Kevin had vanished. However, Tracy told Dr Macphee, she had discovered that he had begun a new affair with an actress he knew, who was playing in repertory 40 miles away. She was pretty sure Kevin could not have told the girl. Was it not Dr Macphee's duty to inform her?

Kevin agreed to come to see $\mathrm{Dr}$ Macphee, but protested that Tracy had made the whole thing up, and that if the doctor acted on false information from a 
jealous woman, he would make serious trouble. He did know that actress as it happened: she belonged to a rather strait-laced religious group and was unlikely to take kindly to the suggestion. But above all Kevin himself would greatly resent it if his confidentiality was breached. If Dr Macphee did that, he would have to find another doctor.

Dr Macphee thought about the problem, decided to maintain confidentiality, and parried Tracy's further enquiries by saying that Kevin was now his problem, not hers. A few weeks later, in his capacity as an expert in HIV medicine at the regional centre, he received a letter from a doctor in the town where the actress was playing. Would Dr Macphee see this young woman, who had an unusual glandular-fever-like illness with pronounced neurological features? The doctor understood that her boy-friend was an ex-drug-user. She too turned out to be infected.

These two examples illustrate ethical tensions related to confidentiality in the context of HIV infection and AIDS. Each example, clearly, is coloured by particular cultural assumptions about men, women, guilt, innocence, sexuality, family life, family doctoring and hospital clinics. But a common feature of both is that a bad situation seems to have been made worse by failure to exploit all the constructive possibilities of the clinician-patient relationship. Dr Browne cut these possibilities short by precipitately raising the question of breaching confidentiality. Dr Macphee also may have done so, by focusing attention on Tracy's claims, rather than by creating an atmosphere in which Kevin was more likely to take his advice about the risks of any further sexual relationships he might have.

Neither Dr Browne and John, nor Dr Macphee and Kevin, in other words, seem to have been successful in establishing a relationship of mutual empowerment. The human limitations and fallibility of individual doctors and patients mean, of course, that this ideal is not always realised in practice. But insofar as it is, it may be possible to avert some of the harmful consequences illustrated above.

The ideal of mutual empowerment is more likely to be achieved, we believe, if patients and the public, as well as clinicians, begin from a realistic understanding of the ethics of medical confidentiality - that there are morally defensible reasons why doctors have a duty to preserve confidentiality in most circumstances and to consider breaching it on some rare occasions.

\section{Guidance and interpretation}

A significant step towards such understanding was taken by the General Medical Council, in its statement of May 1988.

'Questions of conflicting obligations ... arise when a doctor is faced with the decision whether the fact that a patient is HIV positive or suffering from AIDS should be disclosed to a third party, other than another health-care professional, without the consent of the patient. The council has reached the view that there are grounds for disclosure only when there is a serious and identifiable risk to a specific individual who, if not so informed, would be exposed to infection. Therefore, when a person is found to be infected in this way, the doctor must discuss with the patient the question of informing a spouse or other sexual partner. The council believes that most patients will agree to

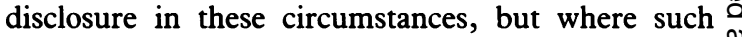
consent is withheld the doctor may consider it a duty to is seek to ensure that any sexual partner is informed, in $\vec{\circ}$ order to safeguard such persons from a possible fatal infection' (4).

What does this authoritative guidance suggest for the examples we have outlined? At first sight, it appears to $\vec{\infty}$ support Dr Browne's view that he would be justified in ${ }_{A}$ telling Jane about John's condition, if John finally $\vec{v}$ refused to do so himself. What the General Medical $\omega$ Council actually says, however, is that a doctor 'may 을 consider it a duty to seek to ensure that any sexual $\rightarrow$ partner is informed': it states neither that the duty is categorical, nor how it should be discharged. (There $\varnothing$ are, in fact, several ambiguities here: 'may consider' 3 could either permit or require; 'a duty' could be either prima facie or categorical; 'seek to' could mean either $\vec{\bullet}$ do his utmost or do a reasonable amount.) In ol second example, therefore, even if Dr Macphee hat good grounds for suspecting that Kevin was not telling him the truth, he too might claim to be following the council's guidance, or at least what that guidance allowed.

Dr Macphee's reasoning might be as follows. In his considered judgement, Tracy's allegation of a 'serious and identifiable risk to a specific individual' was less 3 convincing than Kevin's threat to go elsewhere if his confidentiality was breached. It is not uncommon for doctors to be given information which might be important to third parties, but which they can neither $\overparen{\Phi}$ directly prove nor immediately act upon. Those in $\mathrm{Dr}$ 을 Macphee's position - hospital consultants to whose clinic patients have direct access - cannot influence $\stackrel{O}{?}$ their patients' behaviour by manipulating family or social pressures. If he did go elsewhere, Dr Macphee 을 thought it quite possible that Kevin might infect $\frac{?}{2}$ several other women before he needed to seek further medical assistance. The best chance of avoiding this, $\mathbb{N}$ was for Dr Macphee to maintain confidentiality, make clear to Kevin that he had no illusions, and try to 0 persuade him to undertake not to put any other person $\mathrm{\omega}$ at risk.

Dr Macphee's argument then, is that he interpreted $\stackrel{\circ}{\circ}$ the General Medical Council's guidance in the way he $\Phi$ judged most likely, at the time, to serve the health both ${ }^{+}$ of his patient and of the public. But Dr Browne in our $\frac{7}{3}$ first example, if he disregarded the possibility that $\frac{\vec{D}}{\mathbb{D}}$ John could have infected others, also might have $\frac{\rho}{\odot}$ argued that he was interpreting the guidance with these $\unrhd$ ends in view. Since it seems that the same guidance can be followed either by maintaining or by breaching 
confidentiality, does the choice between these alternatives depend entirely on the individual doctor's fallible judgement about the most likely consequences of his action? Or are there other ethical considerations which, if patients knew of them, might help to make their own doctors' choices seem less arbitrary? This question has been of special concern to people with HIV infection or AIDS, because at an early stage of the epidemic, some patients who voluntarily disclosed their HIV status were then refused treatment or otherwise discriminated against by health care workers. The relevant professional bodies stated firmly that this was unethical, but some patients continued to fear discrimination.

\section{Different doctors, different contexts}

Dr Browne and Dr Macphee were each interpreting the General Medical Council's guidance in a way which probably was consistent with their own moral views and professional experience. Might understanding be assisted therefore, if doctors made their own distinctive interpretation of the General Medical Council's guidance on confidentiality clear to patients as part of their initial contract? Some doctors, for example, might promise that, unlike others, they would maintain confidentiality come what may. Others might promise that they would not breach it unless the patient did something which they had earlier agreed together would provide a reason for this. Others again, who refused to state their position, or were evasive about it, might be judged unlikely to maintain strict confidentiality.

There are three obvious objections to this approach. One is that very few doctors indeed can honestly promise never to breach confidentiality - at least not without the risk that their unstated reservations may become known and damage their credibility. The second is that negotiating conditions for breaching confidentiality is not the best way of initiating a relationship of mutual trust. The third difficulty is that many doctors do not consider it appropriate, or even possible, to make an explicit contract with most of their patients. Some doctors may be anxious to reassure a particular patient constituency that they will not breach confidentiality. But they can rarely ensure that they achieve this before a relationship of trust is established. Within such a relationship their approach can be clarified when necessary. Otherwise they can only hope that their attitude will become known, as their patients get to know them better. In a busy grouppractice, where patients tend to see whatever doctor is available, even this may be an unrealistic expectation.

But if the attitudes of individual doctors to confidentiality cannot readily be distinguished, it may be possible to distinguish the distinctive attitudes of different specialties. This can be illustrated by the fact that two specialties, occupational health and genitourinary medicine, are known to observe particularly strict rules of confidentiality. A similar approach has been adopted in other specialties especially concerned with HIV infection and AIDS; and the possibility that this approach is not shared by all doctors seems to be implicitly recognised in the General Medical Council's advice (5) that when a patient, after counselling, 'still refuses to allow the general practitioner to be informed then the patient's wish for privacy should be respected'.

These observations may help patients to understand one aspect of the ground-rules of medical confidentiality. The specialties mentioned undoubtedly do observe very strict rules. But it would be both inaccurate and invidious to conclude from this that doctors in other specialties or in general practice are any more likely to breach confidentiality. The difference, rather, is that because of their special circumstances, and some legal as well as professional constraints, these specialties tend to interpret General Medical Council policy in a more uniform way than elsewhere in medicine. In other specialties, including general practice, there are many doctors whose approach is just as strict as that of those in the specialties mentioned. Patients have few if any ways of knowing who these doctors are however; and it could be very helpful to them if the profession were seen to be more consistent in its approach to confidentiality.

Because judgements about a variety of factors are normally involved in any decision whether or not to breach confidentiality, it is unlikely that further carefully-worded guidance of the kind provided by the General Medical Council, however correct ethically, can provide what is needed for a more consistent approach. But, building on the General Medical Council's statement, it may be helpful: 1) to identify some moral factors which tend to recur in doctors' decisions about maintaining or breaching confidentiality; 2) to examine the part they play in examples of a variety of decision-making contexts, and 3) to ask if agreement can be reached about making their role more consistent. One of the most important of these moral factors is informed choice.

\section{Informed choice}

The General Medical Council states that a doctor may have a duty to breach confidentiality 'only when there is a serious and identifiable risk to a specific individual who, if not so informed, would be exposed to infection'. This assumes that if the individual were informed, he would choose not to be exposed to infection. A crucial (albeit not the only) moral principle involved here is respect for autonomy.

The well-known application of this principle is in informed consent to medical treatment. If an HIVinfected cardiac surgeon who continues to operate, for example, refuses to disclose his status to anyone but his own doctor in a confidential relationship, his doctor 'has a duty' to breach his confidence and 'to inform an appropriate body' (6). The moral reason for this is not only to avoid harm to the surgeon's patients. It is also 
because, without knowing the surgeon's HIV status, the patients could not give truly informed consent to being operated upon. This would be a crucial moral factor (although this is an extreme example), if that surgeon alone was available to perform a life-saving operation on a patient who, on being informed, was willing to risk infection in the interest of survival.

A further HIV-related example of informed choice is when one drug-abuser is at risk of being infected by sharing needles with another who conceals from him that he is HIV-positive. If both are patients of the same doctor, and the doctor decides to inform the atrisk patient by breaching the other patient's confidentiality, his reasons for doing this presumably include the need to provide him with information which might help him decide against the risk-bearing activity.

But is the doctor justified in breaching confidentiality in this case? It differs from that of the surgeon in at least two significant ways. The first is that needle-sharing, unlike surgery, is one of the surest ways of becoming infected - both because of the direct blood-to-blood contact and because anyone now prepared to do this is already quite likely to be infected. The second difference is that almost all of the information to be given by breaching confidentiality is already public knowledge; and (since in this case the person at risk is the doctor's patient) it is precisely the information of which the doctor should be making every effort to help the patient become aware in relation to his own behaviour.

Taking these features into account, it can be argued that, unless the doctor judges that his efforts have failed to help the at-risk individual become aware of the risks (and hence to make an informed decision against drug-injecting), the doctor has not sufficient reason to breach his other patient's confidentiality. In this case, moreover, the doctor's normal duty to maintain confidentiality is reinforced by the hope that in so doing he may encourage his infected patient to change his behaviour, thereby protecting not only his own uninfected patient, but also others potentially at risk.

The difference between the case of the surgeon and that of the drug abuser suggests a way of distinguishing whether or not it is justifiable to consider breaching confidentiality when there is a risk of sexually transmitted HIV infection. Again, the moral factor of informed choice is central.

If a specific individual, unable to give informed consent to sexual intercourse because of immaturity or mental incapacity, is at risk of being infected by a doctor's patient, or if anyone is at risk of being raped or otherwise assaulted by him, the doctor has a clear duty to breach confidentiality either to the authorities or to the individual at risk. The doctor again has a duty, in this case to consider breaching confidentiality, if an HIV-positive patient refuses to disclose his HIV status to a potential sexual partner, who has no reason to suspect it. If the person at risk also is the doctor's patient, and there is no other way of making him aware of the risk, a breach of confidentiality can be justified by arguing that he cannot make a free choice about having intercourse, without first being informed, by his doctor, of the exceptional unsuspected risks.

\section{Duties to patients}

The ethical implications are more complex, however, if the person at risk is not a patient of the same doctor, or if the person at risk might have reason to suspect that their sexual partner is infected. In the latter case, the patient at risk may appear unaware of what the doctor would consider reasonable grounds for uncertainty about whether or not their potential partner is infected - for example, that they either have had other sexual partners, or have previously contracted a sexually transmitted disease. Since these may still be popularly regarded as less risky forms of behaviour than, for example, needle-sharing, it might be argued that in this case the doctor does have a duty to breach confidentiality, in order to protect the at-risk patient.

There are strong reasons for resisting this argument. What the doctor may consider as a duty, the General Medical Council states, is 'to seek to ensure that any sexual partner is informed, in order to safeguard such persons from a possible fatal infection'. His first duty therefore is to make every effort to ensure that his patient becomes informed of the facts of HIB transmission.

How the doctor chooses to do this without breaching his other patient's confidentiality will depend upon the $\mathrm{e}^{+}$ circumstances. On the rare occasions when this problem arises the doctor may well find ways of solving it without compromising either confidentiality or honesty. But there may be occasions, particularly when there is no apparent reason for his initiative, when this is not possible, and the doctor has to choose either to lie, or to risk awakening the suspicion that he knows more than he admits.

In these exceptional circumstances the doctor's choice will reflect not only how absolute a duty he believes maintaining confidentiality to be, but also his assessment of the consequences of breaching confidentiality, both for the doctor-patient relationship in general, and specifically for the subsequent response of both patients. A crucial factor will be the doctor's judgement about how far, by maintaining confidentiality, he can encourage the infected patient to acknowledge his or her responsibility to respect the interests of others.

Often, however, some way can be found, without directly breaching confidentiality, of ensuring that the at-risk patient becomes able to make his or her own informed choice. Even in the case of John and Jane, for example, Dr Browne might have averted the circumstances in which he felt it necessary to breach confidentiality, if he had been alert earlier to the possible counselling implications of treating a gynaecological condition in the wife of a man living alone for nine months in a part of the world where there is known to be a high risk of HIV infection. 


\section{Duties to others}

What if the person at risk is not the doctor's patient? In this case, the doctor has no ready way, without serious risk of breaching confidentiality, either of discovering if the person at risk is sufficiently informed of the general risks of HIV infection to make an informed choice about intercourse with the infected patient, or of ensuring that this information is acquired by them.

Here again, a crucial aspect of the doctor's decision must be his judgement of how far, by maintaining confidentiality, he can encourage his patient to respect others' interests. In this case moreover, the doctor cannot tell whether the specific individual whom he suspects to be at risk is the only person at risk from his HIV-positive patient. He may quite reasonably decide, therefore, that the most effective way available to him of protecting everyone at risk is by what he hopes to achieve from maintaining confidentiality.

Depending upon how the doctor learns about a possible risk to others, of course, there may still be ways in which he can take some additional action. In the case of Tracy and Kevin, for example, Dr Macphee had neither sufficient grounds, nor the opportunity, to reinforce whatever the actress might know and understand about the risks of HIV infection. But he might have suggested to Tracy that, while he was not justified in informing the actress, she herself might have a responsibility to do this.

A final example illustrates that even when there seem to be the strongest reasons for breaching confidentiality, this may not be practicable. A walk-in clinic doctor was consulted by a young woman who became HIV-positive after a blood transfusion. Some time later, she met a young man, and they both wanted to marry: she was still a virgin and there was nothing in her history to make him suspect that she was infected. She did not want her general practitioner to be informed, but had a good relationship with the clinician. This continued until he began to suggest that she ought to inform the young man, implying that if she did not do so, he might have to. At this, the young woman left the clinic, telling the clinician that there was no point in trying to follow her up, because, fearing from the outset precisely what he had threatened to do, she had given him a false name and address. Since the clinician had relied on the young woman's own account of her medical history and knew only the young man's first name, there was nothing further he could do. He was now unable, in the context of the continuing clinical relationship, to influence the matter further.

\section{Conclusion}

This example is less unrepresentative than it may seem. It is not uncommon for patients attending such clinics to give a false name and address; and the fears which lead them to do so are among the reasons why such clinics exist. This serves as a reminder that all cases in which a doctor may be justified in considering whether to breach confidentiality are exceptions; and that the onus will always lie with the doctor for demonstrating not only that breaching confidentiality is morally justified, but also that it is likely to achieve its intended purpose.

One of the most important reasons for maintaining medical confidentiality, we have argued, is to empower patients to make informed choices about matters vital to their life and health. On very rare occasions, a doctor may have to consider breaching one patient's confidentiality, if this is the only way to protect another's ability to make a crucial informed choice. If he decides to breach confidentiality, however, the doctor may lose his only opportunity of influencing his patient to behave responsibly - and thereby his only opportunity of protecting further individuals with whom the patient may have sexual contact.

This possible consequence may have to be accepted if the doctor judges that breaching confidentiality is the only way to ensure that his at-risk patient, to whom he has a particular responsibility, is informed. (This responsibility is not diminished by the possibility that the at-risk patient may already have been infected, since early diagnosis of HIV infection may have important implications for beneficial treatment.) But when the person at risk is not his patient, the doctor's responsibility is more general and his judgement lesso certain. Thus the doctor may justifiably decide that his general responsibility to all non-patients at risk is besto served by maintaining confidentiality in order to encourage his HIV-positive patient to respect others' interests.

If the medical profession is seen to accept the general principles on which this argument is based, we believe, it will help patients to understand that the ground rules of medical confidentiality, although complex, are consistent and justifiable. If patients have confidence in these ground-rules, moreover, this will encourage the kind of open dialogue and mutual empowerment which makes any need for breaches of confidentiality less likely.

Kenneth M Boyd, MA, BD, PhD, is Director of Research at the Institute of Medical Ethics, and an Honorary Fellow of Edinburgh University Medical Faculty.

\section{Institute of Medical Ethics Working Party on the Ethical Implications of AIDS}

The Rt Hon Sir Patrick Nairne, Chairman.

Professor Brenda Almond, Director, Social Values Research Centre, University of Hull.

Miss Marija Danilunas, Solicitor, Gray's Inn.

Miss Ursula Gallagher, Nursing Adviser, Charing Cross Hospital; Honorary Research Fellow, IME.

Dr Raanan Gillon, General Practitioner; Editor, Fournal of Medical Ethics.

Mr Jonathan Grimshaw, Director, The Landmark. 
Mr Kenneth Howse, Philosopher; Honorary Research Fellow, IME.

Dame Rosalinde Hurley, Professor of Microbiology, Royal Postgraduate Medical School.

Mr Michael Marland, Headmaster, North Westminster Community School.

Professor Anthony Pinching, Professor of Immunology, St Bartholomew's Hospital Medical College.

Mrs Renee Short, Member, Medical Research Council.

Mr Richard Wells, Oncology Nursing Adviser, Royal Marsden Hospital.

Mrs Patricia Wilkie, Research Fellow, St George's Hospital Medical School.

Dr David Zideman, Consultant Anaesthetist,
Hammersmith Hospital.

Dr Kenneth M Boyd, Secretary.

\section{References}

(1) Hippocratic Oath. In: Duncan A S, Dunstan G R, Welbourn R B eds. Dictionary of medical ethics, revised edition. London: Darton, Longman and Todd, 1981: 210.

(2) See reference (1): Declarations: 132.

(3) General Medical Council. Professional conduct and discipline: fitness to practise. London: General Medical Council, 1983: 18-21.

(4) General Medical Council. Statement sent to all doctors in the UK: paragraph 19. IME bulletin 1988; 41, Aug: $5 f$.

(5) See reference (4): paragraph 17.

(6) See reference (4): paragraph 10.

\section{Obituary}

\section{Professor Archie Duncan, DSC, Hon MD (Edin), FRCSE, FRCOG}

Archie Duncan, who died in Edinburgh on 1st October at the age of 78, achieved much in a number of diverse fields, most recently in medical ethics. To that discipline he brought a formidable range of experience and skills acquired over the years in obstetrics, war, medical education and the arcane politics of university life. He was an idealist who would have been embarrassed to be identified as such and at the same time an unsurpassed but utterly modest fixer.

In committee he was a master, with an instant and untiring grasp of issues, personalities and timing. That, with his gift for the short, quiet phrase that bestowed reward, consensus or condign punishment, made him a welcome ally, a feared opponent and a much sought-after chairman. Where lesser doctors affect to despise committee work, he relished it. He simply excelled, and once confided that his obstetric past had been ideal preparation: to confront the unpromising, achieve the unexpected, and do so against a non-negotiable deadline often in the unsociable hours had nurtured, he conceded, certain useful skills over the decades.

$\mathrm{He}$ was born in India, the son of a Church of Scotland missionary, and graduated MB ChB from Edinburgh in 1936. After obstetric training he served from 1941 to 1945 as an RNVR medical officer. His Distinguished Service Cross was awarded for his part in retrieving casualties from his ship, the destroyer HMS Pakenham, prior to her abandonment and sinking after a convoy action in the Mediterranean. It is entirely characteristic of Archie Duncan that even close friends were unaware of the details of this until after his death.
In 1966, while professor of obstetrics and gynaecology in Cardiff, he sustained a myocardial infarction which prompted him to return to Edinburgh as executive dean of the faculty of medicine and professor of medical education. He flourished, and the institution and countless individuals benefited. There have been many beloved doctors, rather fewer beloved administrators. As executive dean Archie Duncan was genial, courteous, wise and untiring. In the late 1960 s, when students throughout Europe were seduced by visions of revolution, Archie's were attending faculty liaison meetings and finding out how the world really worked, and still works. Many of us are permanently indebted to him.

He was an early and important sponsor of the Edinburgh Medical Group and in that capacity played a key role in setting up the research activities of the Institute of Medical Ethics. He jointly edited the Dictionary of Medical Ethics and served on the governing body of the IME for many years. He was a founding consulting editor of the fournal of Medical Ethics. Recognising the importance of medical ethics in medical education, he used his considerable influence to promote it in Edinburgh and elsewhere.

He was a very organised man. To keep track of his many and various schemes, ploys and projects, he used to make notes on little white index cards filed first in his top pocket. In due course, his instructions concerning funeral arrangements were found on one such card. Everything went according to plan. 